\title{
BMJ Open A survey across four European countries to determine rheumatology health professionals' awareness of physical activity measures in people with inflammatory joint diseases
}

Norelee M Kennedy, ${ }^{1,2}$ Sean G McKenna, ${ }^{1}$ Aoife O'Neill, ${ }^{3}$ Bente Appel Esbensen, ${ }^{4,5}$ Thijs Willem Swinnen, ${ }^{6,7}$ Birgitta Nordgren, ${ }^{8,9}$ Sara Willemijns, ${ }^{7}$ Nanna Maria Hammer, ${ }^{4}$ Nina Brodin ${ }^{8,10}$

To cite: Kennedy NM, McKenna SG, O'Neill A, et al. A survey across four European countries to determine rheumatology health professionals' awareness of physical activity measures in people with inflammatory joint diseases. BMJ Open 2018;8:e020809. doi:10.1136/ bmjopen-2017-020809

- Prepublication history and additional material for this paper are available online. To view these files, please visit the journal online (http://dx.doi org/10.1136/bmjopen-2017020809).

Received 5 December 2017 Revised 13 February 2018 Accepted 4 April 2018
Check for updates

For numbered affiliations see end of article.

Correspondence to Dr Norelee M Kennedy; norelee.kennedy@ul.ie

\section{ABSTRACT}

Objectives The objectives of this study were to determine rheumatology health professionals' (HPs)' awareness of and confidence in using physical activity (PA) measures in people with inflammatory joint diseases (IJDs), their own self-reported PA levels and to identify HP-related educational needs.

Methods Rheumatology HPs in Denmark, Sweden, Ireland and Belgium participated in an on-line survey. Descriptive statistics and latent class analysis (LCA) were undertaken SPSS (v21and SASv9.4) to describe data aggregates and range and to identify subclasses of groups with respect to use of PA measures.

Results 322 ( $n=322,75.5 \%$ women) HPs responded from Denmark $(n=50,15.5 \%)$, Sweden $(n=66,20.5 \%)$, Ireland $(n=28,8.7 \%)$ and Belgium $(n=178,55.3 \%)$ and the majority of respondents $(n=286,91.7 \%)$ reported it was important to measure PA in people with IJDs. Only $28.2 \%$ of HPs used simple body worn sensors to measure PA levels in their patients. The majority were interested in on-line education on measuring PA (82.9\%). LCA, used to generate classes of PA measures employed by HPs, revealed three distinct classes reflecting differences in self-reported PA levels, awareness of PA measures, further education requirements and professional background. Conclusions The majority of respondents reported that they considered measuring PA as important in people with IJDs; however, the majority lacked confidence in how to measure it. There was strong interest in further education around measuring PA. Three distinct respondent classes were identified to inform targeted education on how to measure PA.

\section{INTRODUCTION}

Regular physical activity (PA) is associated with improvements in health-related outcomes, such as quality of life, aerobic fitness and disease-related characteristics, including pain and stiffness in people with inflammatory joint diseases (IJDs). ${ }^{1-4}$ However, research has shown lower levels of
Strengths and limitations of this study

- First survey to examine how rheumatology health professionals in four European countries measure physical activity (PA) in their clinical practice and their confidence in doing so.

- The use of latent class data analysis to identify subgroups to aid tailoring of further education relating to PA measurement in clinical practice is novel in this field.

- An overall response rate could not be calculated as two countries could not determine the total sample surveyed.

- Translation of the survey, which was originally designed in English, may have inadvertently led to a reduction in face validity of the survey.

PA in the arthritis population, ${ }^{5-9}$ thus better promotion of PA among people with IJDs is necessary. ${ }^{10}$ Health professionals (HPs) are ideally placed to promote PA and its health benefits with their patients. ${ }^{11}$

Previous studies have investigated attitudes and educational needs relating to health-enhancing PA among HPs in the Netherlands ${ }^{12}$ and Ireland. ${ }^{13}$ However, these studies focused on whether HPs valued PA for people with arthritis and did not focus on how to measure $\mathrm{PA}$ in this population. In order to promote PA and to determine if people with IJDs are engaging in PA, HPs need to be aware of how to measure PA. Accurate measurement of PA is important for clinical decision making and monitoring of changes in outcomes. The range and complexity of devices available to measure PA have increased in recent times. ${ }^{14-16}$ These devices, while presenting an opportunity to measure PA more comprehensively, may be a barrier to PA measurement 
in practice due to their perceived complexity of use, cost and availability in clinical practice. Yet, these devices are increasingly used by patients necessitating that HPs are confidently able to discuss PA measurement using them. ${ }^{1718}$ To inform education aimed at enhancing HPs' knowledge of using PA measures in practice, it is first necessary to survey their current awareness of measuring PA.

Tailored interventions are preferable in changing HPs' practices $^{19}$ and advanced analysis of HPs' characteristics can assist with identifying subgroups for tailored education. Latent class analysis (LCA) is a statistical approach that allows for such identification of subclasses based on response patterns from the overall sample in a survey. ${ }^{20}$

Thus, the aim of this study was to determine rheumatology HPs' awareness of and confidence in using PA measures in people with IJDs. A second aim was to identify subclasses within this population to help tailor further education on use of PA measures for people with IJD.

\section{METHODS}

A survey reporting guideline ${ }^{21}$ was used to guide reporting of this survey (Research checklist).

\section{Design}

A cross-sectional on-line survey design was used to allow a broad geographic distribution, convenience to respondents and guaranteed respondent confidentiality. ${ }^{22}$

\section{Sample}

Rheumatology HPs in Denmark, Sweden, Ireland and Belgium in Europe were invited to participate in an on-line survey. Participants were recruited to participate through their national rheumatology HP association/ group. The Denmark HPs were recruited through the 'Danish Interdisciplinary Rheumatology Forum', 'Occupational Therapists in Rheumatology/Arthritis and Back Disorders' (Facebook group) and through the hospitals' rheumatology departments across the country. The Swedish HPs were recruited through the Swedish Association of Physiotherapists Rheumatology Interest group and the Swedish Rheuma Forum groups for occupational therapists and nurses. In Ireland, recruitment was through the Irish Rheumatology Health Professionals Society and the Irish Society for Rheumatology in Ireland and in Belgium, recruitment was through the Belgian Health Professionals in Rheumatology and Belgian Royal Society for Rheumatology in Belgium. HPs in this study included all HPs working in rheumatology, including medical, nursing and allied HPs. Separate ethical approval was granted by each participating country's research ethics committees.

\section{Survey}

The study steering group developed an on-line survey following review of previously used questionnaires to measure PA among HPs. ${ }^{12} 13$ The questionnaire (online supplementary file 1) was divided into sections ${ }^{\mathrm{i}}$ : demographic profile; PA measurement; aerobic capacity testing and educational needs. As previous studies have noted that some HPs' own PA levels may have an influence on how they advise their patients about being physically active, ${ }^{12} 23$ a measure of HPs' own PA was included. The Short Questionnaire to Assess Health Enhancing Physical Activity (SQUASH) ${ }^{24}$ was chosen based on its previous use with rheumatology $\mathrm{HPs}^{12}$ and its short completion time. The SQUASH contains 11 questions on PA related to commuting activities, leisure time and sports activities, household activities and activity at work and school and is reported to have acceptable reliability (overall reproducibility: $\mathrm{r}=0.58$ ) and validity (correlation with an activity monitor for the total activity score was $\mathrm{r}=0.45) .{ }^{24}$

In this study, the total score used was the total minutes of activity per week as it incorporates frequency and duration of all included activities.

To ascertain face validity of the questionnaire used in this study, discussions were organised in each country by the country representative and up to four other HPs, to cover the different professional groups. These debriefings were held in order to explore whether the constructs surveyed within each questionnaire reflected the aims under study (ie, to identify missing or problematic questions/constructs) and were understandable in each language. No issues relating to conceptualisation in any language following translation were identified. The questionnaire was translated into each country's main language(s). Data were then back-translated where necessary and the final results were presented in English.

\section{Data collection}

The questionnaire was conducted online through SurveyMonkey, KI Survey or SurveyXact. In each country, the chairperson for each relevant HP association was contacted requesting permission for their group's members to participate. When this permission was granted, the chairperson acted as gatekeeper by sending the email containing the study information, survey link and researcher details to their group's members. The first page of the survey contained detailed information on the study and consent was implied if the respondent continued past this page to complete the survey. Reminders were sent to members, via the chairperson, at 1 month post the initial email 3 weeks apart.

\section{Data analysis}

Descriptive statistics of the demographic profile were derived from the data. Categorical data were described as counts and percentages. Continuous data that approximated a Gaussian distribution were described as means

${ }^{\mathrm{i}}$ Parts of the survey on barriers to measurement and aerobic capacity testing will be reported in future papers. 
and SDs, otherwise the continuous data were described as medians and IQRs. Differences between the demographic variables were tested using $X^{2}$ tests and analysis of variance test where appropriate. $\mathrm{LCA},{ }^{20}$ a probability-based model, was used to generate classes of use of measures of PA. A number of latent class models, with one class up to four classes, were compared and two model fit indexes, Akaike information criterion (AIC) $)^{25}$ and Bayesian information criterion (BIC), ${ }^{26}$ were used to identify the optimal number of latent classes. The model with the smallest AIC and BIC indicates the best fitting model. Data analysis was carried out using the SPSS (v21, IBM USA) and SAS (v 9.4, SAS Institute, USA).

\section{RESULTS}

A total of 322 HPs responded to the survey, with country and sociodemographic profiles provided in table 1 . The overall response rate for the survey could not be calculated, as exact membership numbers were not available in each country. On an individual country basis, the response rates were available for Ireland (65\%) and Sweden (25\%) only.

\section{Measuring PA}

When asked about the importance or not of measuring PA in people with IJDs, the majority $(\mathrm{n}=286,91.7 \%)$ stated it was important, while $26 \mathrm{HPs}(8.3 \%)$ said measuring PA was not important (table 1). Of those stating it was not important to measure PA $(n=26)$, the majority $(n=24$, $92 \%$ ) were physiotherapists ( $10 \%$ of overall physiotherapy sample), from Belgium ( $\mathrm{n}=21,80.8 \%)$, were mostly older aged (55-65) (n=11,42\%) with only country differences statistically significantly different $(\mathrm{p}=0.006)$ (table 2$)$.

The majority of HPs $(n=226(87.6 \%))$ wanted further education on PA measurement (table 1). There was strong interest in on-line education with the majority of respondents who answered yes to wanting further education $(n=214,82.9 \%)$ interested in this on-line format.

Respondents were most confident using, educating about and interpreting data from simple body worn sensors (pedometers, simple accelerometers and smartphone apps) and paper questionnaires/diaries and least confident using, educating about and interpreting complex body worn sensors (sensors that collect multiple data on one device) and digital diaries and questionnaires (PA surveys on phones, for example) (table 3). Physiotherapists were likely to use all sensors compared with occupational therapists and nurses, whereas occupational therapists and nurses were most likely to use paper/digital questionnaires (table 4).

Physiotherapists reported greater confidence in using, educating about and interpreting simple and complex body worn devices, which was statistically significant for confidence in using simple devices $(\mathrm{p}<0.005)$, educating patients about simple devices $(\mathrm{p}=0.003)$ and interpreting simple devices only ( $\mathrm{p}=0.023)$ (table 4$)$.

\begin{tabular}{|c|c|c|}
\hline & Variable & Count (\%) \\
\hline \multirow[t]{4}{*}{ Country } & Denmark & $50(15.5)$ \\
\hline & Sweden & $66(20.5)$ \\
\hline & Ireland & $28(8.7)$ \\
\hline & Belgium & $178(55.3)$ \\
\hline \multirow[t]{2}{*}{ Gender } & Female & $243(75.5)$ \\
\hline & Male & $79(24.5)$ \\
\hline \multirow[t]{6}{*}{ Age } & $18-24$ & 7 (2.2) \\
\hline & $25-34$ & $54(16.8)$ \\
\hline & $35-44$ & $81(25.2)$ \\
\hline & $45-54$ & $89(27.6)$ \\
\hline & $55-64$ & $87(27.0)$ \\
\hline & $65-74$ & $4(1.2)$ \\
\hline \multirow[t]{4}{*}{ Profession } & Occupational therapist & $30(9.3)$ \\
\hline & Physiotherapist & $242(75.2)$ \\
\hline & Registered nurse & $42(13.0)$ \\
\hline & Others $†$ & $8(2.5)$ \\
\hline \multirow[t]{8}{*}{ Place of work } & Hospital part-time & $60(18.6)$ \\
\hline & Hospital full-time & $94(29.2)$ \\
\hline & Private part-time & $18(5.6)$ \\
\hline & Private full-time & $104(32.3)$ \\
\hline & Primary part-time & $1(0.3)$ \\
\hline & Primary full-time & $3(0.9)$ \\
\hline & Mixed place of work & $26(8.1)$ \\
\hline & Other & $16(5.0)$ \\
\hline \multirow{7}{*}{$\begin{array}{l}\text { Patients treated } \\
\text { with arthritis - \% }\end{array}$} & $<5 \%$ & $97(30.1)$ \\
\hline & $6-10 \%$ & $63(19.6)$ \\
\hline & $11-25 \%$ & $33(10.2)$ \\
\hline & $26-50 \%$ & $25(7.8)$ \\
\hline & $51-75 \%$ & $26(8.1)$ \\
\hline & $76-100 \%$ & $76(23.6)$ \\
\hline & Other & $2(0.6)$ \\
\hline \multirow{2}{*}{$\begin{array}{l}\text { Important to } \\
\text { measure PA } \\
(n=312)\end{array}$} & Yes & $286(91.7)$ \\
\hline & No & $26(8.3)$ \\
\hline \multirow{2}{*}{$\begin{array}{l}\text { Want further PA } \\
\text { education } \\
(n=258)\end{array}$} & Yes & $226(87.6)$ \\
\hline & No & $32(12.4)$ \\
\hline \multirow{2}{*}{$\begin{array}{l}\text { Want on-line } \\
\text { further education } \\
\text { on PA } \\
(n=258)\end{array}$} & Yes & $214(82.9)$ \\
\hline & No & $44(17.1)$ \\
\hline \multicolumn{2}{|l|}{$\begin{array}{l}\text { SQUASH-(total } \\
\text { minutes per week) } \\
\text { Mean (SD) }\end{array}$} & $3874(2,231.0)$ \\
\hline \multicolumn{3}{|c|}{$\begin{array}{l}{ }^{*} \text { Total } \mathrm{n}=322 \text {. } \\
\text { †Others - podiatrists, rheumatologists, social worker } \\
\text { and pharmacist. }\end{array}$} \\
\hline
\end{tabular}


Table 2 Demographic profile of respondents' views on importance of measuring physical activity

\begin{tabular}{|c|c|c|c|}
\hline \multicolumn{2}{|c|}{ Important to measure } & & \\
\hline $\begin{array}{l}\text { No } \\
(n=26)\end{array}$ & $\begin{array}{l}\text { Yes } \\
(n=286)\end{array}$ & & \\
\hline Count (\%) & Count (\%) & $P$ values & Effect size \\
\hline
\end{tabular}

\begin{tabular}{|ccccc}
\hline Age & & & \\
\hline $18-24$ & $1(3.8)$ & $4(1.4)$ & 0.247 & 0.146 \\
\hline $25-34$ & $3(11.5)$ & $49(17.1)$ & & \\
$35-44$ & $4(15.4)$ & $75(26.2)$ & & \\
$45-54$ & $6(23.1)$ & $82(28.7)$ & & \\
$55-64$ & $11(42.3)$ & $73(25.5)$ & & \\
$65-74$ & $1(3.8)$ & $3(1.0)$ & & \\
Gender & & & & \\
\hline Female & $16(61.5)$ & $222(77.6)$ & 0.065 & 0.105 \\
\hline Male & $10(38.5)$ & $64(22.4)$ & & \\
Country & & & & \\
Denmark & $5(19.2)$ & $45(15.7)$ & $0.006^{\star}$ & 0.199 \\
\hline Sweden & $0(0.0)$ & $66(23.1)$ & & \\
Ireland & $0(0.0)$ & $27(9.4)$ & & \\
\hline Belgium & $21(80.8)$ & $148(51.7)$ & & \\
\hline
\end{tabular}

†Total $n=312$ as 10 respondents did not answer this question.

\section{PA levels}

The SQUASH questionnaire was used to measure HPs' own PA levels (table 5). The mean total minutes of activity per week for the whole sample was 3874.2 (SD 2,231.0) minutes.

\section{Latent class analysis}

LCA was used to generate classes of use of measures of PA. Models with one through four latent classes were compared in order to select a model of activity levels. The BIC suggests that the two-class solution was superior ( $\mathrm{BIC}=99.03)$, while the AIC suggests the three-class solution $(\mathrm{AIC}=46.04)$. An examination of both the two-class and three-class models suggested that the three-class model had greater parsimony (online supplementary file 2). The membership probabilities and the item response probabilities for the three-class LCA solution are presented in online supplementary file 2, while the association between the classes and the sociodemographics is shown in table 6.

- Class 1-traditional group - class membership probability for this class was $34.66 \%$ of individuals. People in this class had a high probability of using paper/ digital means to measure PA, were mainly from Belgium, Sweden and Ireland, tended to be older and had lower years' experience working in rheumatology than Class 3 and greater years' experience in rheumatology than Class 2. They also had the lowest total minutes of activity per week.

- Class 2-reluctant group-resulted in the highest class membership probability, $49.62 \%$. People in this group tended not to use any method of measurement, were older, had the shortest experience working in rheumatology, but the longest years working overall, were mainly nurses and from Belgium and Denmark and had a greater group membership who do not want further education about PA. This group's PA levels were higher than Class 1 but lower than Class 3.

- Class 3-early adopters-class membership probability for this class was $15.72 \%$ of the sample and can be categorised as those who use all methods to measure PA. This groups members were mainly physiotherapists from Belgium and Sweden who were working in rheumatology longer than Class 1 and 2 members and were in agreement as to the importance of measuring $\mathrm{PA}$ and want more education relating to PA. Members of this group also had the highest total minutes of activity per week.

\section{DISCUSSION}

This study is the first to investigate HPs' awareness of and confidence in using measures of PA for people with IJDs across four European countries. PA is an important part of the optimal management of people with IJDs. ${ }^{27-29}$ In addition to promoting PA among people with IJDs, HPs also need to be able to adequately measure PA as an outcome measure. ${ }^{17}$

Our study highlights that the majority of HPs working with people with IJDs in four countries see the importance of measuring PA. However, confidence in using more objective measures of PA was low overall in this survey,

Table 3 Descriptives of confidence in using, educating about and interpreting physical activity measures*

Simple body Complex body

worn sensor worn sensor

Median (IQR) Median (IQR)

\begin{tabular}{|c|c|c|c|c|c|c|}
\hline $\begin{array}{l}\text { Confidence in } \\
\text { using }\end{array}$ & $7.0(7.0)$ & $4.0(8.0)$ & $7.0(7.0)$ & $8.0(6.0)$ & $3.5(7.0)$ & $3.0(6.0$ \\
\hline $\begin{array}{l}\text { Confidence in } \\
\text { educating }\end{array}$ & $5.0(9.0)$ & $2.0(7.0)$ & $8.0(7.5)$ & $6.0(9.0)$ & $2.0(7.0)$ & $2.0(7.0$ \\
\hline $\begin{array}{l}\text { Confidence in } \\
\text { interpreting }\end{array}$ & $6.0(9.0)$ & $3.0(7.0)$ & $7.0(7.0)$ & $6.0(8.0)$ & $4.0(8.0)$ & $3.0(7.0$ \\
\hline
\end{tabular}

${ }^{*}$ Confidence scores legend: possible score range $0-10-0=$ not confident, $10=$ very confident. 
Table 4 Health professionals' confidence in using, educating about and interpreting physical activity (PA) measures by profession ${ }^{*} \dagger$

\begin{tabular}{|c|c|c|c|c|}
\hline & $\begin{array}{l}\text { Occupational } \\
\text { therapist }(n=30)\end{array}$ & Physiotherapist $(\mathrm{n}=242)$ & $\begin{array}{l}\text { Registered } \\
\text { nurse }(n=42)\end{array}$ & Others $¥(n=8)$ \\
\hline & Median (IQR) & Median (IQR) & Median (IQR) & Median (IQR) \\
\hline \multicolumn{5}{|c|}{ Confidence in using PA measures by profession } \\
\hline Simple & $5.0(3.5)$ & $7.0(7.0)$ & $5.0(9.0)$ & $5.5(6.25)$ \\
\hline Complex & $3.5(6.0)$ & $5.0(8.0)$ & $2.0(5.0)$ & $1.0(8.5)$ \\
\hline Paper Q. & $8.0(3.0)$ & $7.0(7.0)$ & $8.0(8.0)$ & $6.5(7.25)$ \\
\hline Paper D. & $8.0(4.25)$ & $6.0(8.0)$ & $6.0(8.0)$ & $5.0(7.25)$ \\
\hline Digital Q. & $5.0(4.25)$ & $3.0(6.0)$ & $5.0(7.5)$ & $5.0(5.5)$ \\
\hline Digital D. & $5.0(4.0)$ & $2.0(6.0)$ & $3.0(7.0)$ & $5.0(5.0)$ \\
\hline \multicolumn{5}{|c|}{ Confidence in educating patients to use PA measures by profession } \\
\hline Simple & $5.0(6.5)$ & $6.0(9.0)$ & $1.0(5.0)$ & $2.0(2.0)$ \\
\hline Complex & $4.0(5.5)$ & $4.0(8.0)$ & $0.0(4.0)$ & $1.0(2.75)$ \\
\hline Paper Q. & $8.0(2.5)$ & $8.0(8.0)$ & $5.0(10.0)$ & $6.5(6.0)$ \\
\hline Paper D. & $8.0(4.5)$ & $6.0(9.0)$ & $5.0(10.0)$ & $5.5(5.25)$ \\
\hline Digital Q. & $6.0(5.0)$ & $2.0(7.0)$ & $2.0(9.0)$ & $5.0(4.75$ \\
\hline Digital D. & $5.0(5.5)$ & $2.0(7.0)$ & $2.0(8.0)$ & $5.0(4.75)$ \\
\hline \multicolumn{5}{|c|}{ Confidence in interpreting results from PA measures by profession } \\
\hline Simple & $6.0(5.0)$ & $7.0(9.0)$ & $2.0(6.0)$ & $1.0(2.25)$ \\
\hline Complex & $4.0(6.0)$ & $4.0(8.0)$ & $0.0(2.5)$ & $0.0(0.5)$ \\
\hline Paper Q. & $9.0(3.0)$ & $7.0(7.0)$ & $7.0(10.0)$ & $4.0(7.0)$ \\
\hline Paper D. & $8.0(4.0)$ & $5.0(8.25)$ & $6.0(9.0)$ & $4.0(7.0)$ \\
\hline Digital Q. & $6.0(4.0)$ & $3.0(8.0)$ & $3.0(7.5)$ & 2.0 (5.25) \\
\hline Digital D. & $5.0(4.0)$ & $2.0(7.0)$ & $2.0(7.0)$ & 2.0 (5.25) \\
\hline
\end{tabular}

${ }^{*}$ Confidence scores legend: possible score range $0-10-0=$ not confident, $10=$ very confident.

†Total $n=322$.

‡Others - podiatrists, rheumatologists, social worker and pharmacist.

Complex, complex body worn sensor; Digital D, digital diary; Digital Q, digital questionnaire; Paper D, paper diary; Paper Q, paper

questionnaire; Simple, simple body worn sensor.

with just a small group of physiotherapists, predominantly from Belgium and Sweden who were experienced in the field of rheumatology most likely to use any body worn sensor to PA measure in their patients. Lack of confidence in measuring PA is not uncommon among HPs. A survey of primary care physicians in Sydney found that less than $30 \%$ of primary care encounters involve PA assessment $t^{30}$ with physicians indicating differing preferences for what instrument to use in practice to measure PA. ${ }^{31}$

Previous research has examined the self-report PA levels of rheumatology $\mathrm{HPs}^{12}$ and reported lower PA levels using the same score (total minutes of activity per week) compared with this study. Physiotherapists' and nurses' total minutes of activity per week were 863 and almost 1000 min higher, respectively, than in the Hurkmans et al study. The SQUASH PA levels reported in this study are very high but reflective of the totality of activity that the respondents reported, including light daily activities during work, getting to and from work and not just structured exercise, which are often not captured. The differences between our SQUASH results and that of the previous Dutch study ${ }^{12}$ may be explained by greater awareness among HPs of the importance of regular PA for their own health in the intervening time between the two studies, the inclusion of different countries in this study and the use of different aggregate values in both studies.

The majority of respondents wanted further education on PA measurement and the majority would like this in an on-line format. Development of more tailored education programmes are preferable for changing HPs' practices. ${ }^{32}$ To help identify if differences existed between countries, professions, place of work and rheumatology experience, we used a statistical approach to determine if different groupings existed regarding use of PA measures. The three groups modelled using LCA showed that while a majority were aware of measures of PA, respondents in the reluctant group are a priority for education as they had the lowest awareness of PA measures. The value of using LCA to generate classes of use of measures of PA in this study is in aiding the tailoring of further PA education, which may in turn enhance participant's confidence in measuring 


\begin{tabular}{|c|c|c|c|}
\hline & SQUASH mean (SD) & $P$ values & $\eta^{2}$ \\
\hline \multicolumn{4}{|l|}{ Sex } \\
\hline Female $(n=183)$ & 3859.1 (2205.6) & 0.841 & 0.000 \\
\hline Male $(n=49)$ & $3931.1(2345.7)$ & & \\
\hline \multicolumn{4}{|l|}{ Age } \\
\hline $18-24(n=3)$ & $6286.7(2737.3)$ & 0.062 & 0.045 \\
\hline $25-34(n=36)$ & 4717 (2088.3) & & \\
\hline $35-44(n=64)$ & $3576(2348.1)$ & & \\
\hline $45-54(n=67)$ & 3720.9 (2076.7) & & \\
\hline $55-64(n=60)$ & 3725.5 (2248.2) & & \\
\hline $65-75(n=2)$ & $4223.0(229.1)$ & & \\
\hline \multicolumn{4}{|l|}{ Country } \\
\hline Denmark $(n=41)$ & $3781.5(1478.5)$ & $<0.000^{\star}$ & 0.248 \\
\hline Sweden $(n=46)$ & $2881.3(1385.8)$ & & \\
\hline Ireland $(n=27)$ & $1662.9(914.6)$ & & \\
\hline Belgium ( $n=118)$ & $4808.7(2390.5)$ & & \\
\hline \multicolumn{4}{|l|}{ Profession } \\
\hline $\begin{array}{l}\text { Occupational } \\
\text { therapist }(n=16)\end{array}$ & 3118.1 (2029.6) & 0.361 & 0.014 \\
\hline $\begin{array}{l}\text { Physiotherapist } \\
(n=180)\end{array}$ & 3986.6 (2219.2) & & \\
\hline Registered nurse $(n=31)$ & 3759.7 (2388.6) & & \\
\hline Others $\ddagger(n=5)$ & $2959.0(2193.1)$ & & \\
\hline
\end{tabular}

*Total minutes of activity per week.

†Total $n=232$ as not all respondents completed SQUASH data. ‡Others-podiatrists, rheumatologists, social worker and pharmacist. SQUASH, Short Questionnaire to Assess Health Enhancing Physical Activity.

PA. Generic approaches to delivery of education can result in reduced uptake of the education with resultant lack of change in practice. Based on the results of this study, people in the reluctant group should be targeted first as they do not report measuring PA as important and did not report an interest in further education on measuring PA. Members in the reluctant group were from all four countries (majority from Belgium and Denmark), all three professions (highest physiotherapy) and were the longest qualified group, but working the least years in rheumatology. Their reluctance may be part formed by an assumption of expertise in this area based on length of experience and/or a view that not all HPs need to be educated in measuring PA. An education programme for this group around measurement of PA would need to take a graded approach starting with a basic introduction to the value of PA measurement and the various methods of doing so in a clinical setting. This learning could then be contextualised to rheumatology incorporating case studies to allow for application of learning. Members of the traditional group were most likely to already use a basic form of PA measurement, thus an intermediate level module focusing on the range of PA measures and how to interpret data from them would form the basis for their learning. Finally, the minority of respondents belonging to the early adopters group were most likely to be already using all methods of PA measurement —-for this group, a more advanced educational module could be developed incorporating theories of PA behavioural change and advanced PA measurement. These educational modules may also need to consider differing professional scopes of practice around PA measurement and management. The use of a statistical approach to develop groups to help target educational interventions has been used in other areas of practice, including antibiotic use and resistance in Sweden ${ }^{33}$ and nurses beliefs about caring for patients traumatic brain injury. ${ }^{34}$ In this study, the use of LCA to generate classes of use of measures of PA was valuable in helping to identify subgroups with similar scores who have different scores from the other subgroups. ${ }^{20}$ Further research using qualitative methods would build on these findings to explore educational needs among respondents within each subgroup.

\section{Implications for practice}

While measuring PA was reported as important by HPs in these four European countries, there is not a concomitant high number of HPs measuring PA in practice. Measuring $\mathrm{PA}$ is important as engagement in $\mathrm{PA}$ is important for patients and has numerous health benefits. Thus, it can become a routine outcome measure in practice. Encouraging practitioners to use some of the range of measures available to measure PA is important given the importance of PA in managing IJDs. To improve the use of PA outcome measures in practice, it is necessary for HPs to improve their awareness of and confidence in using objective measures of PA.

\section{Limitations}

As with any survey, respondents may have misinterpreted the questions with resultant inaccuracy in responses. The original survey was designed in English and translated into Swedish, Danish, French and Flemish with results being reported into English. Hence, some understanding or interpretation may have been lost in translation and back-translation. We identified no changes in interpretability following translation; however, future studies should undertake a more rigorous process with regard to translation and back-translation and should undertake large-scale cross-cultural validity work prior to undertaking the final survey. Some information on the benefits of PA measurement provided in the introduction to the questionnaire and some questions may have had a leading effect on respondents.

Also, respondents were largely physiotherapists, occupational therapists and nurses, thus the results cannot be considered to be reflective of the views of other rheumatology HPs, including rheumatologists. Rheumatologists are an important group to consider when examining how to promote $\mathrm{PA},{ }^{35}$ thus further research is needed to determine their awareness of PA measures in people with IJDs. Finally, response rates were estimates only for two countries as exact membership numbers for those countries were not available. 
Table 6 Association between latent classes and sociodemographics

\begin{tabular}{|c|c|c|c|c|c|}
\hline & Class 1 & Class 2 & Class 3 & \multirow[b]{4}{*}{$P$ values } & \multirow[b]{4}{*}{ Effect size† } \\
\hline & (Traditional) & (Reluctant) & (Early adopters) & & \\
\hline & $(n=91)$ & $(n=157)$ & $(n=42)$ & & \\
\hline & Count (\%) & Count (\%) & Count (\%) & & \\
\hline \multicolumn{6}{|l|}{ Country } \\
\hline Denmark & 9 (9.89) & $40(25.48)$ & $1(2.38)$ & \multirow[t]{4}{*}{$<0.001^{\star}$} & \multirow[t]{4}{*}{0.276} \\
\hline Sweden & $32(35.16)$ & $17(10.83)$ & $17(40.48)$ & & \\
\hline Ireland & $12(13.19)$ & $14(8.92)$ & $0(0.0)$ & & \\
\hline Belgium & 38 (41.76) & $86(54.78)$ & $24(57.14)$ & & \\
\hline \multicolumn{6}{|l|}{ Gender } \\
\hline Female & 71 (78.02) & $126(80.25)$ & 30 (71.43) & \multirow[t]{2}{*}{0.467} & \multirow[t]{2}{*}{0.073} \\
\hline Males & 20 (21.98) & 31 (19.75) & $12(28.57)$ & & \\
\hline \multicolumn{6}{|l|}{ Age } \\
\hline $18-24$ & $1(1.10)$ & $3(1.91)$ & $0(0.0)$ & \multirow[t]{6}{*}{0.741} & \multirow[t]{6}{*}{0.109} \\
\hline $25-34$ & $14(15.38)$ & $26(16.56)$ & $8(19.05)$ & & \\
\hline $35-44$ & $26(28.57)$ & 36 (22.93) & 14 (33.33) & & \\
\hline $45-54$ & $25(27.47)$ & $52(33.12)$ & $9(21.43)$ & & \\
\hline $55-64$ & 25 (27.47) & $37(23.57)$ & $10(23.81)$ & & \\
\hline $65-74$ & $0(0.0)$ & $3(1.91)$ & $1(2.38)$ & & \\
\hline \multicolumn{6}{|l|}{ Profession } \\
\hline Occupational therapist & $14(15.38)$ & $12(7.64)$ & $1(2.38)$ & \multirow[t]{4}{*}{$0.001 \dagger$} & \multirow[t]{4}{*}{0.195} \\
\hline Physiotherapist & $63(69.23)$ & $112(71.34)$ & $41(97.62)$ & & \\
\hline Registered nurse & $14(15.38)$ & $27(17.20)$ & $0(0.0)$ & & \\
\hline Other & $0(0.0)$ & $6(3.82)$ & $0(0.0)$ & & \\
\hline \multicolumn{6}{|l|}{ Place of work } \\
\hline Hospital part-time & $22(24.18)$ & 25 (15.92) & $11(26.19)$ & \multirow[t]{8}{*}{0.344} & \multirow[t]{8}{*}{0.164} \\
\hline Hospital full-time & $26(28.57)$ & $51(32.48)$ & $11(26.19)$ & & \\
\hline Private part-time & $2(2.20)$ & $11(7.01)$ & 2 (4.76.) & & \\
\hline Private full-time & $25(27.47)$ & $49(31.21)$ & $13(30.95)$ & & \\
\hline Primary care part-time & $0(0.0)$ & $0(0.0)$ & $1(2.38)$ & & \\
\hline Primary care full-time & $2(2.20)$ & $1(0.64)$ & $0(0.0)$ & & \\
\hline Mixed practice & $9(9.89)$ & $11(7.01)$ & $3(7.14)$ & & \\
\hline Other & $5(5.49)$ & $9(5.73)$ & $1(2.38)$ & & \\
\hline \multicolumn{6}{|l|}{ Important to measure } \\
\hline No & $2(2.20)$ & $20(12.74)$ & $0(0.0)$ & \multirow[t]{2}{*}{$0.001 \dagger$} & \multirow[t]{2}{*}{0.213} \\
\hline Yes & $89(97.80)$ & $137(87.26)$ & $42(100.0)$ & & \\
\hline \multicolumn{6}{|l|}{ PA education } \\
\hline No & $5(5.62)$ & $25(18.94)$ & $2(5.41)$ & \multirow[t]{2}{*}{$0.005 \dagger$} & 0.203 \\
\hline Yes & 84 (94.38) & $107(81.06)$ & 35 (94.59) & & \\
\hline ACT education & & & & & \\
\hline No & 8 (8.99) & 31 (22.96) & $3(8.57)$ & $0.009 \dagger$ & 0.191 \\
\hline Yes & 81 (91.01) & $104(77.04)$ & 32 (91.43) & & \\
\hline Years qualified & & & & & \\
\hline Median (IQR) & $20(17)$ & $24(18)$ & $20.5(17)$ & 0.996 & $<0.001$ \\
\hline Years rheumatology & & & & & \\
\hline Median (IQR) & $12(13)$ & $9(20)$ & $16(21)$ & $0.015 \dagger$ & 0.03 \\
\hline SQUASH & & & & & \\
\hline $\begin{array}{l}\text { Total minutes of activity per } \\
\text { week, Mean (SD) }\end{array}$ & 3626.67 (2439.94) & $3949.98(21.28 .98)$ & 4274.36 (1995.48) & 0.33 & 0.01 \\
\hline
\end{tabular}

*Statistically significant relationship.

tCramer's $V$ effect size is used for categorical variables, otherwise $\eta^{2}$ is used.

ACT, aerobic capacity testing; PA, physical activity; SQUASH, Short QUestionnaire to ASsess Health Enhancing Physical Activity. 
The SQUASH questionnaire has mixed evidence for its reliability and validity in patients with ankylosing spondylitis $^{36}$ and total knee arthroplasty ${ }^{37}$ and in non-clinical populations ${ }^{24} 38$ with one recent study identifying its considerable variation in test-retest reliability and validity among a multiethnic population in The Netherlands. ${ }^{39}$ We would not recommend the use of this measure of self-report PA based on what we identified, but were unable to verify, in the absence of an observational study, if over-reporting of PA levels occurred. Respondents were not asked to detail if their work and home were urban or rural locations, which limited the interpretation of the SQUASH data.

\section{CONCLUSION}

The majority of the rheumatology HPs reported that it was important to measure PA; however, levels of awareness and confidence were moderate to low about how to use, interpret and educate patients about more complex measures such as body worn devices. There was strong interest in further education around measuring PA. Three distinct subgroups were identified allowing for targeted education and training for HPs to be developed in future to improve knowledge and confidence in using PA measures.

\section{Research reporting checklist}

The following reporting checklist was used in the preparation of this manuscript-Good Practice in the conducting and reporting of survey research. ${ }^{21}$

\section{Author affiliations}

${ }^{1}$ Discipline of Physiotherapy, School of Allied Health, University of Limerick, Limerick, Ireland

${ }^{2}$ Health Research Institute, University of Limerick, Limerick, Ireland

${ }^{3}$ Department of Mathematics and Statistics, University of Limerick, Limerick, Ireland

${ }^{4}$ Copenhagen Center for Arthritis Research, Center for Rheumatology and Spine

Diseases, Centre of Head and Orthopaedics, Rigshospitalet, Glostrup, Denmark

${ }^{5}$ Department of Clinical Medicine, University of Copenhagen, Copenhagen, Denmark

${ }^{6}$ Division of Rheumatology, UZ Leuven, Leuven, Belgium

${ }^{7}$ Department of Development and Regeneration, Skeletal Biology and Engineering

Research Center, KU Leuven, Leuven, Belgium

${ }^{8}$ Division of Physiotherapy, Department of Neurobiology, Care Sciences and Society, Karolinska Institutet, Stockholm, Sweden

${ }^{9}$ Karolinska University Hospital, Stockholm, Sweden

${ }^{10}$ Division of Physiotherapy, Orthopaedic Clinic, Danderyd University Hospital, Stockholm, Sweden

Contributors NK, NB, BAE, BN and TS were the original authors who submitted the grant, designed the study, oversaw the data collection and analysis in their countries, assisted with preparation of the paper and read and commented on all drafts and agreed on the final manuscript. SGMcK, SW and NMH were research assistants who assisted with designing the survey, collecting the data, analysing the data and commented on manuscript drafts. AO'N undertook the substantive analysis of the data, including the latent class analysis, and also commented on all manuscript drafts.

Funding This study was funded by the European League Against Rheumatism Health Professionals Research Grant 2015.

Competing interests None declared.

Patient consent Not required.
Ethics approval University of Limerick research ethics committee 2015_09_02_EHS.

Provenance and peer review Not commissioned; externally peer reviewed.

Data sharing statement Individual participant data that underlie the results reported in this article, after deidentification (text, tables and appendices), immediately after publication for 3 years to any researchers who provide a methodologically sound proposal. Requests for data sharing should be directed to norelee.kennedy@ul.ie.

Open Access This is an Open Access article distributed in accordance with the Creative Commons Attribution Non Commercial (CC BY-NC 4.0) license, which permits others to distribute, remix, adapt, build upon this work non-commercially, and license their derivative works on different terms, provided the original work is properly cited and the use is non-commercial. See: http://creativecommons.org/ licenses/by-nc/4.0/

(C) Article author(s) (or their employer(s) unless otherwise stated in the text of the article) 2018. All rights reserved. No commercial use is permitted unless otherwise expressly granted.

\section{REFERENCES}

1. Plasqui G. The role of physical activity in rheumatoid arthritis. Physiol Behav 2008;94:270-5.

2. Metsios GS, Stavropoulos-Kalinoglou A, Sandoo A, et al. Vascular function and inflammation in rheumatoid arthritis: the role of physical activity. Open Cardiovasc Med J 2010;4:89-96.

3. Stavropoulos-Kalinoglou A, Metsios GS, Veldhuijzen van Zanten JJ, et al. Individualised aerobic and resistance exercise training improves cardiorespiratory fitness and reduces cardiovascular risk in patients with rheumatoid arthritis. Ann Rheum Dis 2013;72:1819-25.

4. Hurkmans E, van der Giesen FJ, Vliet Vlieland TP, et al. Dynamic exercise programs (aerobic capacity and/or muscle strength training) in patients with rheumatoid arthritis. Cochrane Database Syst Rev 2009;4:CD006853.

5 Tierney M, Fraser A, Kennedy N. Physical activity in rheumatoid arthritis: a systematic review. J Phys Act Health 2012;9:1036-48.

6. Sokka T, Häkkinen A, Kautiainen $\mathrm{H}$, et al. Physical inactivity in patients with rheumatoid arthritis: data from twenty-one countries in a cross-sectional, international study. Arthritis Rheum 2008;59:42-50.

7. Hootman JM, Macera CA, Ham SA, et al. Physical activity levels among the general US adult population and in adults with and without arthritis. Arthritis Rheum 2003;49:129-35.

8. Haglund E, Bergman S, Petersson IF, et al. Differences in physical activity patterns in patients with spondylarthritis. Arthritis Care Res 2012;64:1886-94.

9. Swinnen TW, Scheers T, Lefevre J, et al. Physical activity assessment in patients with axial spondyloarthritis compared to healthy controls: a technology-based approach. PLoS One 2014;9:e85309.

10. Austin S, Qu H, Shewchuk RM. Health care providers' recommendations for physical activity and adherence to physical activity guidelines among adults with arthritis. Prev Chronic Dis 2013;10:E182.

11. Larkin L, Gallagher S, Fraser A, et al. If a joint is hot it's not the time: health professionals' views on developing an intervention to promote physical activity in rheumatoid arthritis. Disabil Rehabil 2017;39.

12. Hurkmans EJ, de Gucht V, Maes S, et al. Promoting physical activity in patients with rheumatoid arthritis: rheumatologists' and health professionals' practice and educational needs. Clin Rheumatol 2011;30:1603-9.

13. McKenna S, Kelly G, Kennedy N. FRI0585-HPR A Survey of Irish Physiotherapists' Current Practice in Promoting Physical Activity in Rheumatoid Arthritis. Ann Rheum Dis 2014;73(Suppl 2):1206.3-7.

14. Tierney M, Fraser A, Purtill $H$, et al. Study to determine the criterion validity of the SenseWear Armband as a measure of physical activity in people with rheumatoid arthritis. Arthritis Care Res 2013;65:888-95.

15. Semanik P, Song J, Chang RW, et al. Assessing physical activity in persons with rheumatoid arthritis using accelerometry. Med Sci Sports Exerc 2010;42:1493-501.

16. Sylvia LG, Bernstein EE, Hubbard JL, et al. Practical guide to measuring physical activity. J Acad Nutr Diet 2014;114:199-208.

17. Trost SG, O'Neil M. Clinical use of objective measures of physical activity. Br J Sports Med 2014;48:178-81.

18. Ainsworth B, Buchholz SW. How to Assess Physical Activity in Clinical Practice and for Scholarly Work. The Journal for Nurse Practitioners 2017;13-14-20 https://doi.org/. 
19. Baker R, Camosso-Stefinovic J, Gillies C, et al. Tailored interventions to address determinants of practice. Cochrane Database Syst Rev 2015;4:CD005470.

20. Kongsted A, Nielsen AM. Latent Class Analysis in health research. J Physiother 2017;63:55-8.

21. Kelley K, Clark B, Brown V, et al. Good practice in the conduct and reporting of survey research. Int J Qual Health Care 2003;15:261-6.

22 Domholdt E. Rehabilitation research: principles and applications: Elsevier Saunders, 2005

23. Iversen MD, Eaton HM, Daltroy LH. How rheumatologists and patients with rheumatoid arthritis discuss exercise and the influence of discussions on exercise prescriptions. Arthritis Care Res 2004:51:63-72.

24. Wendel-Vos GC, Schuit AJ, Saris WH, et al. Reproducibility and relative validity of the short questionnaire to assess health-enhancing physical activity. J Clin Epidemiol 2003;56:1163-9.

25 Akaike H. Factor Analysis and AIC. Springer series in statistics (Perspectives in Statistics). New York, NY: Springer, 1987.

26. Schwarz G. Estimating the Dimension of a Model. The Annals of Statistics 1978;6:461-4.

27. Veldhuijzen van Zanten JJ, Rouse PC, Hale ED, et al. Perceived Barriers, Facilitators and Benefits for Regular Physical Activity and Exercise in Patients with Rheumatoid Arthritis: A Review of the Literature. Sports Med 2015;45:1401-12.

28. Agca R, Heslinga SC, Rollefstad S, et al. EULAR recommendations for cardiovascular disease risk management in patients with rheumatoid arthritis and other forms of inflammatory joint disorders: 2015/2016 update. Ann Rheum Dis 2017;76

29. Withall J, Haase AM, Walsh NE, et al. Physical activity engagement in early rheumatoid arthritis: a qualitative study to inform intervention development. Physiotherapy 2016;102-264-71 https://doi.org/.

30. Winzenberg T, Reid P, Shaw K. Assessing physical activity in general practice: a disconnect between clinical practice and public health? Br J Gen Pract 2009;59:359-67.
31. Dutton SN, Dennis SM, Zwar N, et al. An explorative qualitative study on acceptability of physical activity assessment instruments among primary care professionals in southern Sydney. BMC Fam Pract 2016;17:138.

32. Baker R, Camosso-Stefinovic J, Gillies C, et al. Tailored interventions to overcome identified barriers to change: effects on professional practice and health care outcomes. Cochrane Database Syst Rev 2010:CD005470

33. Vallin M, Polyzoi M, Marrone G, et al. Knowledge and Attitudes towards Antibiotic Use and Resistance - A Latent Class Analysis of a Swedish Population-Based Sample. PLoS One 2016;11:e0152160.

34. Oyesanya TO, Thomas MA, Brown RL, et al. Nurses' Beliefs About Caring for Patients With Traumatic Brain Injury. West $J$ Nurs Res 2016;38:1114-38.

35. Iversen MD, Eaton HM, Daltroy LH. How rheumatologists and patients with rheumatoid arthritis discuss exercise and the influence of discussions on exercise prescriptions. Arthritis Rheum 2004;51:63-72.

36. Arends S, Hofman M, Kamsma YPT, et al. AB0910 Validity and reliability of the IPAQ and squash to assess daily physical activity in patients with ankylosing spondylitis. Ann Rheum Dis 2013;71(Suppl 3):690.16-690.

37. Wagenmakers R, van den Akker-Scheek I, Groothoff JW, et al. Reliability and validity of the short questionnaire to assess healthenhancing physical activity (SQUASH) in patients after tota hip arthroplasty. BMC Musculoskelet Disord 2008;9:141 http:// europepmc.org/abstract/MED/18928545

38. Chinapaw MJ, Slootmaker SM, Schuit AJ, et al. Reliability and validity of the Activity Questionnaire for Adults and Adolescents (AQuAA). BMC Med Res Methodol 2009;9:58.

39. Nicolaou M, Gademan MG, Snijder MB, et al. Validation of the SQUASH Physical Activity Questionnaire in a Multi-Ethnic Population: The HELIUS Study. PLoS One 2016;11:e0161066. 